\title{
Cambios en el tratamiento de la tuberculosis
}

\author{
VICTORINO FARGA C.*
}

\section{Changes in the treatment of tuberculosis}

In order to bring up to date the Technical Norms of the Program of Control and Elimination of Tuberculosis, the Ministry of Health has accepted the following changes: a) perform susceptibility testing to all patients; $b$ ) increase in the frequency of the second phase of treatment from twice to three times a week; c) lower dosage of ethambutol; d) continuation of ethambutol during the second phase of treatment in cases smear positive in the second month of therapy; e) prolongation of treatment to 9 months in some cases; f) elimination of the previous Secondary Treatment; g) elimination of the previous Treatment Simplify, and h) changes in the retreatment of multi-resistant cases (TB-MDR).

Key words: Chemotherapy, tuberculosis, changes, program.

\section{Resumen}

Frente a la necesidad de actualizar las Normas Técnicas del Programa de Control y Eliminación de la Tuberculosis (PROCET), que datan del año 2005, el Ministerio de Salud ha aceptado la recomendación del Equipo Asesor del Ministerio de modificar el tratamiento de la tuberculosis según las últimas recomendaciones internacionales. Se detallan los principales cambios: a) practicar estudio de susceptibilidad a todos los enfermos, nuevos o antes tratados; b) aumentar la frecuencia de la administración de la segunda fase del tratamiento de dos a tres veces por semana; c) disminución de las dosis de etambutol; d) mantención de etambutol en la fase intermitente de tratamiento en los casos que sigan con baciloscopias positivas al segundo mes de la terapia; e) prolongación del tratamiento a 9 meses en casos cavitarios muy avanzados, en aquellos que persisten con baciloscopias positivas al segundo mes de tratamiento y en los co-infectados con el VIH; f) eliminación del Esquema Secundario en los casos "antes tratados"; g) eliminación del Esquema Simplificado en los enfermos con bacteriología no demostrada, $y$ h) cambios del Esquema de Retratamiento en los pacientes portadores de tuberculosis multirresistentes (TB-MDR).

Palabras clave: Quimioterapia, tuberculosis, esquemas, cambios, programa, normas.

El Programa de Control y Eliminación de la Tuberculosis (PROCET) ha demostrado ser muy exitoso en nuestro país. Chile, de tener durante gran parte del siglo pasado las cifras de tuberculosis más elevadas de América, ostenta ahora una de las tasas más bajas de la enfermedad. Esto se debe, en gran parte, al sostenido apoyo político de sucesivos gobiernos, que han adoptado el objetivo sanitario de lograr la eliminación de la tuberculosis, como problema de Salud Pública, en el curso de una generación, y a la adecuada aplicación de las medidas más efectivas para el control de esta enfermedad a través de la incorporación oportuna de nuevos avances médicos.

$\mathrm{Al}$ enfrentarnos con la necesidad de actualizar las Normas Técnicas del PROCET, que datan del año 2005, el Ministerio de Salud ha aceptado la recomendación del Equipo Asesor del Ministerio de modificar el tratamiento de la tuberculosis según las últimas recomendaciones internacionales. En esta breve presentación intentaré explicar las razones de los principales cambios en los esquemas antituberculosos actuales. Pero, es recomendable revisar también las nuevas Normas del PROCET donde se detallan todas las otras modificaciones del programa.

El tratamiento normado de la tuberculosis comprendía hasta hace poco 4 esquemas diferenciados según distintas categorías de pacientes (Tabla 1): 1) Esquema Primario para los

* Miembro del Comité Asesor de Tuberculosis del Ministerio de Salud de Chile. 
enfermos nuevos con bacteriología positiva, los llamados Vírgenes a Tratamiento (VT); 2) Esquema Secundario para las recaídas y los abandonos recuperados, los llamados Antes Tratados; 3) Esquema Primario Simplificado para los pacientes con bacteriología negativa, presuntos portadores de tuberculosis con menor población bacilar, y 4) Esquemas de Retratamiento para enfermos con tuberculosis multirresistentes (TB-MDR y TB-XDR) (Tabla 1).

\section{Cambios en el esquema primario}

\subsection{Practicar estudio de susceptibilidad inicial en todos los pacientes}

En la etapa en que está actualmente el PROCET en la que nos estamos acercando, lentamente, a la eliminación de la tuberculosis como Problema de Salud Pública en Chile, constituye un gran avance conocer lo más precozmente posible después de iniciado el tratamiento, tanto en los pacientes nuevos como en los antes tratados, la sensibilidad inicial a las drogas que se están empleando.

\subsection{Cambio de la segunda fase de tratamiento, desde 2 a 3 veces por semana}

El Esquema primario, indicado para el tratamiento de enfermos nuevos con bacteriología positiva, consistía en la asociación de isoniacida, rifampicina, pirazinamida y etambutol, administradas diariamente, de lunes a viernes, hasta completar 50 dosis, equivalentes a dos meses, en forma totalmente supervisada, seguido por un esquema de tratamiento intermitente 2 veces por semana, administrado hasta completar 32 dosis, es decir durante 4 meses, también en forma totalmente supervisada (Tabla 2).

El primer cambio, en el cual había insistido la Organización Panamericana de la Salud (OPS) durante mucho tiempo, consiste en aumentar la frecuencia de la segunda fase del tratamiento, desde 2 a 3 veces por semana. Chile se resistió durante mucho tiempo a esta modificación porque está demostrado que los resultados del tratamiento son igualmente efectivos cuando es administrado 2 ó 3 veces por semana, a condición que lo sea bajo completa supervisión. Sin embargo, es sabido que la mayoría de los enfermos, aún con los controles más estrictos, se saltan algunas dosis, por lo cual el tratamiento 3 veces por semana es más seguro, porque permite cierto grado de irregularidad sin perder su eficacia (Tabla 3 ).

Los pacientes fuera del rango de peso más frecuente $(45-70 \mathrm{~kg})$ recibirán las dosis $/ \mathrm{kg}$ de peso según la Tabla 4.

\subsection{Disminución de las dosis de etambutol}

Siguiendo las recomendaciones internacionales, se ha reducido la dosis de etambutol desde $1.200 \mathrm{mg}$ a $800 \mathrm{mg}$ en la fase diaria, equivalentes a alrededor $15 \mathrm{mg} / \mathrm{kg}$ para pacientes de $40-70 \mathrm{~kg}$ de peso, y a $1.400 \mathrm{mg}$, equivalentes a $30 \mathrm{mg} / \mathrm{kg}$, en la fase intermitente de 3 veces por semana, con el objeto de disminuir la posibilidad de toxicidad ocular a este medicamento (Tabla 3 ).

Cuando se demuestre resistencia inicial a la isoniacida o cuando este dato se desconozca y la baciloscopia permanezca positiva al segundo

Tabla 1. Esquemas en el tratamiento de la tuberculosis

1. Esquema primario: Enfermos nuevos con bacteriología positiva (VT)

2. Esquema secundario: Recaídas y abandonos recuperados (AT)

3. Esquema primario simplificado: Enfermos nuevos con bacteriología negativa.

4. Esquema de retratamiento: Fracasos de tratamientos anteriores (TB-MDR)

Tabla 2. Tratamiento de la tuberculosis con bacteriologia positiva

\begin{tabular}{|lcc|}
\hline Drogas (mg) & $\begin{array}{c}\text { Fase diaria } \\
\mathbf{5 0} \text { dosis-2 meses } \\
\mathbf{4 5 - 7 0 ~} \mathbf{~ k g}\end{array}$ & $\begin{array}{c}\text { Fase bisemanal } \\
\text { 32 dosis-4 meses }\end{array}$ \\
Isoniacida & 300 & 800 \\
Rifampicina & 600 & 600 \\
Pirazinamida & 1.500 & \\
Etambutol & 1.200 & \\
\hline
\end{tabular}

En enfermos de pesos inferiores a $45 \mathrm{~kg}$ o superiores a $70 \mathrm{~kg}$ deberán ajustarse las dosis por $\mathrm{kg}$ de peso.

Tabla 3. Cambios en esquema primario (VT y AT) (practicar estudio de susceptibilidad inicial en todos los casos)

\begin{tabular}{|lcc|}
\hline Drogas (mg) & $\begin{array}{c}\text { Fase diaria } \\
\text { 50 dosis-2 meses } \\
\mathbf{4 5 - 7 0 ~ k g}\end{array}$ & $\begin{array}{c}\text { Fase trisemanal } \\
\text { 48 dosis-4 meses }\end{array}$ \\
Isoniacida & 300 & 600 \\
Rifampicina & 600 & 600 \\
Pirazinamida & 1.500 & \\
Etambutol & 800 & $(1.400)$ \\
\hline
\end{tabular}

En enfermos de pesos inferiores a $45 \mathrm{~kg}$ o superiores a $70 \mathrm{~kg}$ deberán ajustarse las dosis por kg de peso. VT: vírgenes a tratamiento. AT: tratados anteriormente. 
Tabla 4. Dosis y presentación de los fármacos de primera línea

\begin{tabular}{|c|c|c|c|c|}
\hline Farmacos & $\begin{array}{l}\text { Dosis diaria } \\
\text { (mg/kg) }\end{array}$ & $\begin{array}{l}\text { Dosis trisemanal } \\
(\mathrm{mg} / \mathrm{kg})\end{array}$ & Presentación & Dosis máxima \\
\hline Isoniacida & $5(4-6)$ & $10(8-12)$ & $\begin{array}{l}\text { Comprimidos blancos ranura- } \\
\text { dos de } 100 \mathrm{mg}\end{array}$ & $\begin{array}{l}400 \mathrm{mg} \text { diario } \\
600 \mathrm{mg} \text { trisemanal }\end{array}$ \\
\hline Rifampicina & $10(10-12)$ & $10(10-12)$ & $\begin{array}{l}\text { Cápsulas de } 150 \mathrm{mg} \text { y jarabe } \\
\text { de } 5 \mathrm{mg} / 100 \mathrm{~mL}\end{array}$ & $600 \mathrm{mg}$ diario o trisemanal \\
\hline Pirazinamida & $25(20-30)$ & $35(30-40)$ & $\begin{array}{l}\text { Comprimidos blancos de } \\
500 \mathrm{mg}\end{array}$ & 1.500 diario; 2.500 trisemanal \\
\hline Etambutol & $15(15-20)$ & $30(25-35)$ & Comprimidos de $200 \mathrm{mg}$ & 1.200 diario; 2.000 trisemanal \\
\hline Estreptomicina & $15(12-18)$ & $15(12-18)$ & Frascos de $1 \mathrm{~g}$ & $\begin{array}{l}1 \mathrm{~g} \text { en }<50 \text { años; } 500 \mathrm{mg} \text { en } \\
>50 \text { años }\end{array}$ \\
\hline
\end{tabular}

Al ajustar la dosis por kg de peso de cada fármaco es recomendable elegir la dosis superior más próxima a la calculada.

Tabla 5. Esquema primario con dosis fijas combinadas*

\begin{tabular}{|llcc|}
\hline Fase & Contenido del comprimido (mg) & $\begin{array}{c}\text { n de } \\
\text { comprimidos }\end{array}$ & Dosis \\
Diaria & $\begin{array}{l}\text { Rifampicina } 150 \mathrm{mg} \text {, Isoniacida } 75 \mathrm{mg} \text {, Pirazinamida } 400 \mathrm{mg} \mathrm{y} \\
\text { Etambutol } 275 \mathrm{mg}\end{array}$ & 4 & 50 dosis \\
Trisemanal & Rifampicina $150 \mathrm{mg}$; Isoniacida $150 \mathrm{mg}$ & 4 & 48 dosis \\
\hline
\end{tabular}

*Para enfermos de 45-70 kg de peso. En pacientes con pesos inferiores a $40 \mathrm{~kg}$ o superiores a $70 \mathrm{~kg}$ deberán ajustarse las dosis por kg de peso, sin sobrepasar las dosis máximas diarias o trisemanales según la Tabla 4. Los enfermos con daño hepático previo, insuficiencia renal crónica avanzada o con alergia conocida a alguno de los medicamentos del esquema, no deben usar fármacos en dosis fijas combinadas. Estos pacientes deben ser evaluados por el neumólogo de referencia para la indicación de su tratamiento.

mes de tratamiento, deberá mantenerse la administración de etambutol durante la segunda fase, hasta la negativización de la baciloscopia o hasta que se demuestre sensibilidad a la isoniacida (Tabla 3).

\subsection{Tratamiento con dosis fijas combinadas de medicamentos}

La administración del tratamiento en dosis fijas combinadas (DFC) tiene grandes ventajas operacionales. Cuando se utilice esta presentación, el esquema de tratamiento será el que se muestra en la Tabla 5.

Los enfermos con daño hepático previo, insuficiencia renal crónica avanzada o con alergia conocida a alguno de los medicamentos del esquema, no deben usar fármacos en dosis fijas combinadas. Estos pacientes deben ser evaluados por el neumólogo de referencia para la indicación de su tratamiento.

\subsection{Prolongación del tratamiento a 9 meses}

Es así como para el tratamiento de la tuberculosis en Chile disponemos ahora de sólo dos grandes esquemas, uno utilizado en los pacientes

\section{Tabla 6. Tratamiento actual de la tuberculosis}

1. Esquema primario: Enfermos nuevos (VT) y antes tratados (AT) (Prolongando el tratamiento a 9 meses en casos especiales)

2. Esquema de retratamiento: Fracasos de tratamientos anteriores (TB-MDR)

portadores de tuberculosis probablemente sensibles y otro para los portadores de cepas resistentes. En la mayoría de los casos el tratamiento se mantiene con una duración total de 6 meses. Sin embargo, en casos cavitarios muy avanzados, en aquellos que persisten con baciloscopias positivas al segundo mes de tratamiento y en los co-infectados con el VIH, el neumólogo de referencia del programa podrá prolongar el esquema inicial a nueve meses (Tabla 6).

\section{Eliminación del esquema secundario en enfermos antes tratados (AT)}

Los pacientes que recaen después de un tratamiento exitoso o que abandonan la terapia y 
son recuperados con baciloscopias positivas, los llamados antes tratados (AT), deberán recibir el mismo esquema primario, prolongando la terapia a 9 meses en los casos más avanzados (Tabla 3).

Así, se elimina el llamado esquema secundario en el que se "reforzaba" con el agregado de estreptomicina la primera fase de tratamiento, en circunstancias que estos enfermos, que han sido tratados bajo supervisión, generalmente mantienen su sensibilidad a las drogas empleadas y, aun en el caso que hayan desarrollado resistencia a una de ellas, el empleo de las otras tres es suficiente para prevenir su fracaso con amplificación de la resistencia bacteriana.

\section{Eliminación del esquema simplificado en enfermos con bacteriología negativa}

El esquema simplificado, con la asociación de sólo 3 drogas en la primera fase de tratamiento se indicaba en pacientes en los cuales, al no tener demostración bacteriológica, se asumía que tenían escasa población bacilar y no necesitaban una terapia tan intensiva. Sin embargo, frecuentemente es difícil hacer esta discriminación en la práctica. Por esto y por las ventajas que tiene estandarizar los tratamientos, la Organización Mundial de la Salud (OMS) recomienda ahora tratar a todos los casos iniciales con el mismo esquema primario (Tabla 3 ).

\section{Cambios en el tratamiento de la tuberculosis multirresistente (TB-MDR)}

Los esquemas de tratamiento recomendados para los pacientes portadores de cepas de $M$. tuberculosis resistente por lo menos a isoniacida y rifampicina se basan fundamentalmente en recomendaciones de expertos, más que en investigaciones cooperativas internacionales. Por esto en Chile siempre se han empleado esquemas basados en la experiencia local, los que frecuentemente han diferido de las recomendaciones de la OMS, más aplicables a países menos desarrollados.

La Comisión Asesora del Ministerio de Salud recomienda ahora un esquema de retratamiento consistente en la asociación de tres fármacos de uso excepcional, no empleados en el esquema primario: moxifloxacina $(\mathrm{M})$, kanamicina $(\mathrm{K})$ y etionamida (Et), y dos fármacos recibidos sólo durante los dos primeros meses del esquema primario que fracasó, para los cuales existe menor probabilidad de resistencia adquirida: etambutol
(E) y pirazinamida (Z). Estos medicamentos se administrarán diariamente, de lunes a domingo en los pacientes hospitalizados y de lunes a viernes, bajo supervisión directa del personal del consultorio, en los tratados ambulatoriamente (Tabla 7).

La fase inicial consiste en la administración diaria de moxifloxacina, kanamicina, etionamida, pirazinamida y etambutol (KMEtZE) durante 4 meses. En caso que la baciloscopia persista positiva al cuarto mes, deberá prolongarse el tratamiento con las 5 drogas hasta la negativización de la baciloscopia en dos muestras mensuales consecutivas.

La fase de continuación consiste en la administración diaria de moxifloxacina, etionamida, pirazinamida y etambutol (MEtZE), en las mismas dosis, durante por lo menos 6 meses después de negativizado el cultivo en dos muestras mensuales consecutivas, con una duración total del tratamiento que no podrá ser menor a un año.

Cuando el estudio de susceptibilidad demuestre resistencia a pirazinamida o etambutol, se consultará con el Nivel Central la posibilidad de cambiar el esquema de retratamiento.

Las dosis de los fármacos antituberculosos de segunda línea se muestran en la Tabla 8. Puede ser necesario, especialmente en pacientes añosos, iniciar el tratamiento con pequeñas dosis de los medicamentos para facilitar su tolerancia, incrementándolas en días sucesivos hasta alcanzar las dosis plenas.

El control de la evolución se debe realizar incluyendo una baciloscopia con cultivo, mensualmente, hasta el final del tratamiento. La persistencia de baciloscopias positivas o su reaparición como positiva al $6^{\circ}$ mes o en cualquier control posterior, debe constituir sospecha de fracaso del retratamiento, con amplificación de la resistencia, lo que debe ser confirmado por cultivos positivos y el estudio de susceptibilidad correspondiente.

Toda prescripción de esquema de retrata-

Tabla 7. Esquema normado de retratamiento

\begin{tabular}{|lcc|}
\hline Drogas (mg) & $\begin{array}{c}\text { Fase inicial } \\
\text { ( } \geq \text { 4 meses) }\end{array}$ & $\begin{array}{c}\text { Fase continuación } \\
\text { ( } \geq \text { 12 meses) }\end{array}$ \\
Kanamicina & $750^{*}$ & - \\
Etionamida & 750 & 750 \\
Moxifloxacina & 400 & 400 \\
Pirazinamida & 1.500 & 1.500 \\
Etambutol & 800 & 800 \\
\hline
\end{tabular}

En enfermos de pesos inferiores a $45 \mathrm{~kg}$ o superiores a $70 \mathrm{~kg}$ deberán ajustarse $* 500 \mathrm{mg}$ en pacientes de más de 50 años. 
Tabla 8. Dosis y presentación de los fármacos de segunda línea

\begin{tabular}{|lcll|}
\hline Farmacos & $\begin{array}{c}\text { Dosis diaria } \\
\text { (mg/kg) }\end{array}$ & Presentación & Dosis máxima \\
Etionamida & 15 & Comprimidos de $250 \mathrm{mg}$ & $1.000 \mathrm{mg}$ \\
Kanamicina & 15 & Frasco de $1 \mathrm{~g}$ & $1.000 \mathrm{mg} ; 500 \mathrm{mg}$ en $>50 \mathrm{años}$ \\
Moxifloxacina & $6-10$ & Comprimidos de $400 \mathrm{mg}$ & $400 \mathrm{mg}$ \\
Cicloserina & 15 & Cápsulas de $250 \mathrm{mg}$ & $1.000 \mathrm{mg}$ \\
PAS* & 200 & Comprimidos $0,5 \mathrm{y} 1$ g sobres 4 g y bolsa granel & \\
\hline
\end{tabular}

*PAS: ácido para-aminosalicílico.

miento deberá ser comunicada de inmediato por correo electrónico al Nivel Central del PROCET a través de la ficha de notificación de pacientes con $T B-M D R$, para la solicitud de los fármacos de segunda línea, a la cual se debe anexar el estudio de susceptibilidad a todas las drogas empleadas.

La cirugía de resección pulmonar puede ser considerada como tratamiento complementario en algunos casos específicos de TB-MDR, siempre que cumpla con los siguientes requisitos: lesiones localizadas; reserva cardio-respiratoria adecuada, y falta de un número suficiente de fármacos efectivos que aseguren que se dispone de un esquema curativo.

Desafortunadamente, existe un reducido número de infortunados pacientes que son resistentes no sólo a isoniacida-rifampicina, sino también a quinolonas e inyectables como kanamicina. Son los portadores de tuberculosis extensamente resistentes (TB-XDR), mucho más difíciles de curar con quimioterapia. Para ellos y para los más infortunados aún, los resistentes a todas o casi todas las drogas de acción antituberculosa, sólo cabe intentar Esquemas Individualizados, con asociaciones de 6 y más drogas de menor eficacia.

En la Tabla 9 se resumen los principales cambios que se han adoptado para el tratamiento actual de la tuberculosis en la población adulta en Chile.

\section{Esquemas de tratamiento de la tuberculosis infantil}

El tratamiento de la tuberculosis en el niño no difiere substancialmente del tratamiento de la enfermedad en el adulto, salvo en el ajuste de las dosis de los medicamentos por $\mathrm{kg}$ de peso, las que siguiendo las recomendaciones internacionales, han sido aumentadas en la población infantil (Tabla 10). El esquema primario se indica sólo en los niños portadores de tuberculosis con bacteriología positiva.
Tabla 9. Cambios en el tratamiento de la tuberculosis

- Practicar estudio de susceptibilidad en todos los enfermos

- Tratamiento tres veces por semana en la segunda fase

- Esquema primario para todos los enfermos vírgenes a tratamiento y antes tratados

- Prolongación del tratamiento a 9 meses en casos especiales

- Simplificación del esquema de retratamiento

Tratamiento estrictamente supervisado (DOT)

Tabla 10. Tratamiento de la tuberculosis infantil confirmada bacteriológicamente

\begin{tabular}{|lcc|}
\hline $\begin{array}{l}\text { Fármaco } \\
\text { (mg/kg) }\end{array}$ & $\begin{array}{c}\text { Fase diaria } \\
\mathbf{5 0} \text { dosis } \\
(\mathbf{2} \text { meses- } \\
\mathbf{1 0} \text { semanas) }\end{array}$ & $\begin{array}{c}\text { Fase trisemanal } \\
\mathbf{4 8} \text { dosis } \\
\text { (4 meses- } \\
\text { 16 semanas) }\end{array}$ \\
Isoniacida & $10 \mathrm{mg} / \mathrm{kg}$ & $15 \mathrm{mg} / \mathrm{kg}$ \\
Rifampicina & $15 \mathrm{mg} / \mathrm{kg}$ & $20 \mathrm{mg} / \mathrm{kg}$ \\
Pirazinamida & $35 \mathrm{mg} / \mathrm{kg}$ & \\
Etambutol & $20 \mathrm{mg} / \mathrm{kg}$ & \\
\hline
\end{tabular}

En los casos de tuberculosis no confirmados bacteriológicamente podrá utilizarse un esquema sin etambutol en la primera fase (2HRZ/H3R3) y en la forma más benigna de la tuberculosis infantil, el complejo primario simple, con menor población bacilar, se podrá emplear un esquema primario más simplificado (2HR/4H3R3).

En los casos con tuberculosis no demostradas bacteriológicamente, que son la mayoría a estas edades, en la primera fase de tratamiento se indica una asociación de sólo tres drogas, isoniacida, rifampicina y pirazinamida. Por otra parte, en el complejo primario simple se pueden utilizar sólo dos medicamentos, isoniacida y rifampicina, durante los primeros dos meses de tratamiento. 
En las nuevas Normas Técnicas del PROCET se detallan estos cambios.

\section{Nuevas drogas antituberculosas}

Tenemos que estar preparados para futuros cambios en el tratamiento de la tuberculosis. En los últimos años, frente a la amenaza de una nueva epidemia de tuberculosis resistente cada vez a más drogas, se han intensificado las investigaciones en búsqueda de nuevos fármacos activos frente a esta enfermedad. En la Tabla 11 se presenta una lista de los más prometedores, entre los cuales hay dos que ya se están empleando en el tratamiento de las tuberculosis multirresistentes.

Más aún, existe gran expectación entre los investigadores con la reciente demostración de que una asociación de sólo 3 drogas, de acción predominantemente esterilizante, un nitromidazol, el delamid, asociado a moxifloxacina y pirazinamida, han demostrado ser capaces de curar todas las formas de tuberculosis, sensibles y multirresistentes, en plazos menores a los 6 meses que requiere el esquema primario actualmente y a los 20 y más meses que se indican para los esquemas de retratamiento.

Tenemos que estar atentos a nuevos cambios en el tratamiento de la tuberculosis que permitan seguir abreviando los esquemas actuales.

\section{Tabla 11. Nuevas drogas antituberculosas}

- Nuevas rifamicinas (rifabutina, rifapentina, rifalazid)

- Nuevas quinolonas (levofloxacina, moxifloxacina, gatifloxacina)

- Diarylquinolinas (TMC-207)...Bedaquilina

- Oxazolidinomas (linezolid, PNU-100480, AZT-5847)

- Nitroimidazoles (PA-824, OPC-67683)... Delamid

- Pyrroles (LL3858)

- Diaminas (SQ109)

\section{Bibliografía}

1.- MINISTERIO DE SALUD. Manual de Organización y Normas Técnicas. Programa Nacional de Control de la Tuberculosis. Santiago. Chile. 2005.

2.- WORLD HEALTH ORGANIZATION. Global Tuberculosis Report 2012. WHO/HTM/TB/2012.6.

3.- MINISTERIO DE SALUD. Programa de Control y Eliminación de la Tuberculosis. Informe de situación 2008-2011. Santiago. Chile. 2012.

4.- HERRERA T. La situación de la tuberculosis en Chile y los actuales desafíos. Rev Chil Enf Respir 2013; 29: 46-9.

Correspondencia a:

Dr. Victorino Farga C.

Avda. Providencia 2608 Piso 3

Santiago. Chile

Email: vfarga@gmail.com 